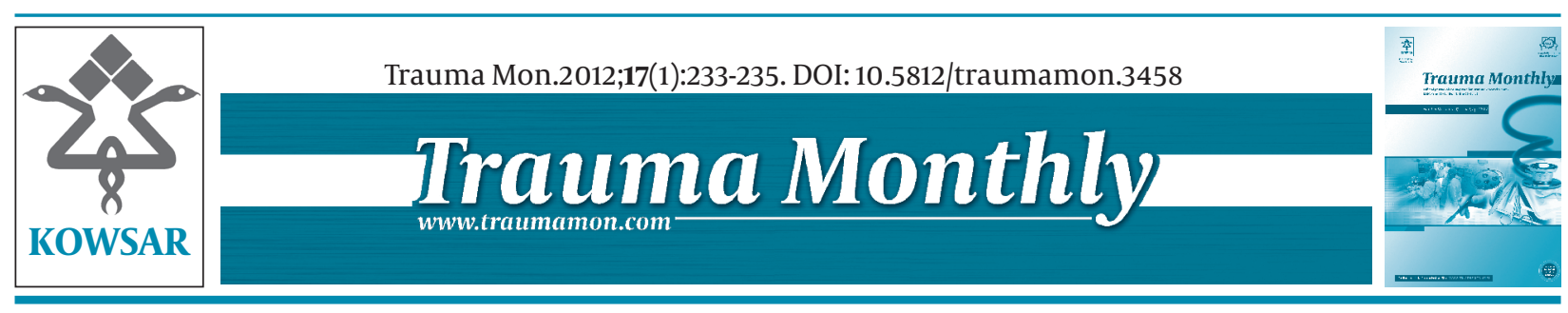

\title{
Intramuscular Midazolam for Pediatric Sedation in the Emergency Department: A Short Communication on Clinical Safety and Effectiveness
}

\author{
Mohammad Reza Ghane ${ }^{1}$, Seyed Yasin Musavi Vaezi ${ }^{1}$, Amir Abbas Hedayati Asl ${ }^{2}$, Hamid \\ Reza Javadzadeh ${ }^{1}$, Sadrollah Mahmoudi ${ }^{1}$, Amin Saburi ${ }^{3^{*}}$ \\ ${ }^{1}$ Trauma Research Center, Baqiyatallah University of Medical Sciences, Tehran, IR Iran \\ ${ }^{2}$ Pediatric Department, Baqiyatallah University of Medical Sciences, Tehran, IR Iran \\ ${ }^{3}$ Chemical Injury Research Center, Baqiyatallah University of Medical Sciences, Tehran, IR Iran
}

A R T I C L E I N F O

Article type:

Original Article

\section{Article history:}

Received: 08 Nov 2011

Revised: 21 Feb 2012

Accepted:30 Feb 2012

\section{Keywords:}

Injections

Intramuscular

Midazolam

Safety

Sedation

Euphoria

\begin{abstract}
A B S T R A C T
Background: Procedural sedation in children continues to be a problem in the emergency department (ED). Midazolam is the first water-soluble benzodiazepine and it has been widely used for procedural sedation in pediatric patients.

Objectives: The aim of this study was evaluation of clinical safety and effectiveness of intramuscular Midazolam for pediatric sedation in the ED setting.

Materials and Methods: We performed a self-controlled clinical trial on 30 children who referred to the Baqiyatallah Hospital ED between 2009 and 2010. They received intramuscular Midazolam $0.3 \mathrm{mg} / \mathrm{kg}$ for procedural sedation and then they were followed for sedative effectiveness and safety. Vital signs and $\mathrm{O} 2$ saturation were also observed. The findings were compared using SPSS ver. 16 software.

Results: The mean age was $5.50 \pm 2.70$ years, the mean weight was $19.50 \pm 6.63$ kilograms and 16 patients (53.3\%) were females. The most common adverse effect was euphoria (66.66\%) and vertigo (6.7\%); $27.7 \%$ did not show any side effects. There was an overall complication rate of 72.3\%. The vital signs including heart rate, respiratory rate, systolic and diastolic blood pressure and $\mathrm{O} 2$ saturation decreased significantly during sedation (Pvalue $<0.05$ ).

Conclusions: Midazolam is an effective and relatively safe sedative for pediatric patients in the ED. The patient should be observed closely and monitored for psychological and hemodynamic side effects.
\end{abstract}

Copyright $\odot 2012$, Kowsar Corp. All rights reserved.

\section{Implication for health policy/practice/research/medical education:}

This paper discusses the use of midazolam for pediatric sedation in the emergency department and assess its clinical safety and effectiveness.

\section{- Please cite this paper as:}

Ghane MR, Musavi Vaezi SY, Hedayati Asl AA, Javadzadeh HR, Mahmoudi S, Saburi A. Intramuscular Midazolam for Pediatric Sedation in Emergency Department: A Short Communication on Clinical Safety and Effectiveness. Trauma Mon. 2012;17(1):233-5. DOI: 10.5812 /traumamon.3458

*Corresponding author: Amin Saburi, Chemical Injury Research Center, Baqiyatallah University of Medical Sciences, Mollasadra st, Vanak sq, Tehran, IR Iran. Tel: +98-9127376851. Email: aminsaburi@yahoo.com

DOI:10.5812/traumamon.3458

Copyright @2012, Kowsar Corp. All rights reserved.

\section{Background}

Procedural sedation in children continues to be a problem in the emergency department (ED). Midazolam is a benzodiazepine that has been widely used for procedural sedation in adults (1). Various sedatives such as pentobarbital, propofol, fentanyl, ketamine and methohexital have been suggested for pediatric sedation but it seems that the selection of sedative agents was based on pref- 
erence(2). The literature has little documentation on midazolam safety and efficacy in pediatric emergency departments; but there is an increasing interest to use midazolam for pediatric sedation and analgesia(3). We used intra-muscular (IM) midazolam to provide sedation for imaging in ED and then evaluated the efficacy and safety of midazolam for sedation and anxiety of children in the ED.

\section{Objectives}

The aim of this study was evaluation of clinical safety and effectiveness of intramuscular midazolam for pediatric sedation.

\section{Materials and Methods}

We conducted a before-after clinical trial on a highly selective group of 30 children between 2 and 12 years-old. The children who presented to the ED of the Baqiyatallah Hospital between 2009 and 2010 were enrolled. The patients that met the inclusion criteria received intramuscular midazolam $0.3 \mathrm{mg} / \mathrm{kg}$, before imaging (CT-Scan or magnetic resonance imaging). Midazolam was administrated at least 30 minutes before beginning the procedure. Sedation, irritability and cooperation scores were followed every 15 minutes during the first hour after receiving the drug. Five stages for sedation were assessed (4).

Also, the vital signs and $\mathrm{O}_{2}$ saturation were observed

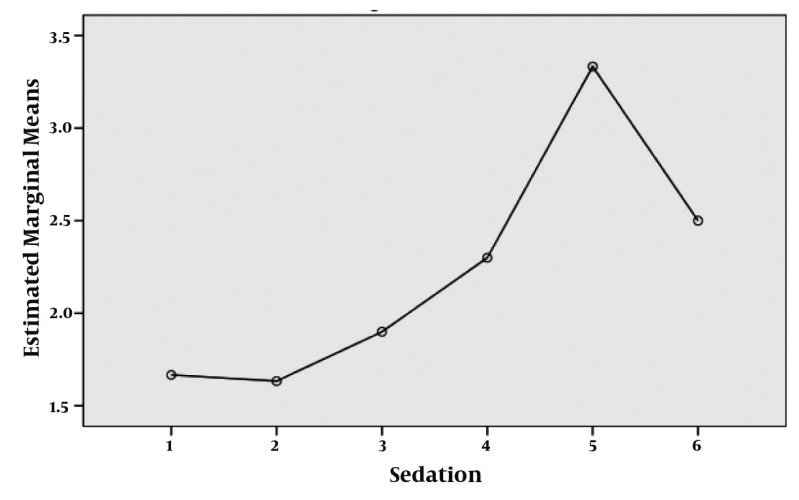

Figure 1. Changes in Sedation Score before, 5 minute, 15, 30, 45 and 60 minutes after injection. during the sedation. The findings were analyzed by using t-test, Chi-square and repeated measure ANOVA SPSS ver. 16; and $P$ value $<0.05$ was considered statistically significant. This study was approved by ethics committee of our university and the parents filled an informed consent before enrollment.

\section{Results}

The mean age was $5.50 \pm 2.70$ years, the mean weight was $19.50 \pm 6.63 \mathrm{Kg}$ and 16 patients (53.3\%) were female. All of the patients were sedated completely after the first dose. The trend of sedation staging progressed to deep sleep; irritability progressed to complete calmness (Figure $1 \&$ Table 1). These trends were statistically significant ( $P$ value $<0.001)$

The mean $\mathrm{O}_{2}$ saturation at first was $97.50 \pm 1.30$ that at the last check changed to $96.33 \pm 1.68$. The trend of $\mathrm{O}_{2}$ saturation changes during sedation had significant decreases $(P$ value $=0.000)$. None of the children suffered hypoxemia $\left(\mathrm{O}_{2}\right.$ saturation under $\left.90 \%\right)$. The mean $\mathrm{RR}$ at the onset was $22.23 \pm 6.54$; at the last visit it changed to $18.80 \pm 4.81$. Also the mean of HR at the onset was 112.46 \pm 14.82 and at the last visit it changed to $103.90 \pm 14.57$. The trends of RR and HR changes had significant decreases $(P$ value $<0.001)$. Moreover, the trends of systolic and diastolic BP changes also had significant decreases ( $P$ value $<0.001)$.

There was an overall side effect rate of $72.3 \%$. The most common was euphoria (66.66\%) followed by vertigo (6.7\%); $27.7 \%$ did not present any side effects. All of the adverse effects resolved by observation only.

\section{Discussion}

Effectiveness of midazolam compared closely to other routine sedative agents such as propofol, fentanyl and ketamine (5, 6). Midazolam IM for temporary short-term pediatric sedation was safe and effective; the greatest sedative impact occurred 45 minutes after injection consistent with other investigations $(3,5,6)$. Demographic characteristics such as age were not influential on the alteration of vital signs.

Psychological side effects such as hallucination and agitation have been commonly reported for benzodiaz-

\begin{tabular}{|c|c|c|c|c|c|c|c|c|c|c|c|c|}
\hline \multirow[b]{2}{*}{ Score } & \multicolumn{5}{|c|}{ Sedation } & \multicolumn{4}{|c|}{ Irritability } & \multicolumn{3}{|c|}{ Cooperation } \\
\hline & 1 & 2 & 3 & 4 & 5 & 1 & 2 & 3 & 4 & 1 & 2 & 3 \\
\hline Before prescription, \% & 60 & 20 & 16.6 & 0 & 3.4 & 20 & 53.3 & 26.6 & 0 & 80 & 10 & 10 \\
\hline 5 Min after prescription, \% & 60 & 23.3 & 13.3 & 0 & 3.4 & 16.6 & 56.6 & 26.6 & 0 & 76.6 & 13.3 & 10 \\
\hline 10 Min after prescription, $\%$ & 40 & 36.6 & 20 & 0 & 3.4 & 13.3 & 50 & 36.6 & 0 & 56.6 & 30 & 13.3 \\
\hline 15 Min after prescription, \% & 23.3 & 33.3 & 36.6 & 3.4 & 3.4 & 6.6 & 16.6 & 73.3 & 3.4 & 30 & 40 & 30 \\
\hline 30 Min after prescription, $\%$ & 10 & 10 & 30 & 36.6 & 13.3 & 13.3 & 36.6 & 43.3 & 3.4 & 6.6 & 20 & 73.3 \\
\hline 45 Min after prescription, $\%$ & 6.6 & 10.0 & 40 & 26.6 & 16.6 & 3.4 & 56.6 & 36.6 & 3.4 & 6.6 & 26.6 & 66.6 \\
\hline 60 Min after prescription, $\%$ & 26.6 & 20 & 33.3 & 26.6 & 3.4 & 0 & 20 & 56.6 & 23.3 & 16.6 & 40 & 43.3 \\
\hline$P$ value & \multicolumn{5}{|c|}{$<0.001$} & \multicolumn{4}{|c|}{$<0.001$} & \multicolumn{3}{|c|}{$<0.001$} \\
\hline
\end{tabular}


epines but euphoria with this high incidence has been reported rarely. One reason for this high incidence might be race (7-9). Previous studies have shown considerable alteration in vital signs as an adverse effect of midazolam; these changes have been temporary $(3,10)$. On the other hand, insufficient dose may not able to provide a deep sedation and further doses may increase the risk of serious side-effects $(11,12)$. Although, mentioned changes was dose dependent, it seems reasonable that the patient under sedation be observe closely. It seems that children who receive intramuscular midazolam may be susceptible to vital signs alterations. Further investigation with a control group and larger sample size and other forms of midazolam administration (such as rectal suppositories) is recommended.

\section{Acknowledgements}

We would like to thank the parents of children who cooperated in this study.

\section{Financial Disclosure}

None declared.

\section{Funding/Support}

None declared.

\section{References}

1. Bell A, Taylor DM, Holdgate A, MacBean C, Huynh T, Thom O, et al. Procedural sedation practices in Australian Emergency Depart- ments. Emerg Med Australas. 2011;23(4):458-65.

2. Mace SE, Barata IA, Cravero JP, Dalsey WC, Godwin SA, Kennedy RM, et al. Clinical policy: evidence-based approach to pharmacologic agents used in pediatric sedation and analgesia in the emergency department. Ann Emerg Med. 2004;44(4):342-77.

3. Singh R, Kumar N, Vajifdar H. Midazolam as a sole sedative for computed tomography imaging in pediatric patients. Paediatr Anaesth. 2009;19(9):899-904.

4. Collins VJ. Principles of anesthesiology: general and regional anesthesia.3th ed.: Lea \& Febiger; 2006.

5. Moro-Sutherland DM, Algren JT, Louis PT, Kozinetz CA, Shook JE. Comparison of intravenous midazolam with pentobarbital for sedation for head computed tomography imaging. Acad Emerg Med. 2000;7(12):1370-5.

6. Alp H, Orbak Z, Guler I, Altinkaynak S. Efficacy and safety of rectal thiopental, intramuscular cocktail and rectal midazolam for sedation in children undergoing neuroimaging. Pediatr Int. 2002;44(6):628-34.

7. Ozdemir D, Kayserili E, Arslanoglu S, Gulez P, Vergin C. Ketamine and midazolam for invasive procedures in children with malignancy: a comparison of routes of intravenous, oral, and rectal administration.J Trop Pediatr. 2004;50(4):224-8.

8. Wenzel RR, Bartel T, Eggebrecht H, Philipp T, Erbel R. Central-nervous side effects of midazolam during transesophageal echocardiography. J Am Soc Echocardiogr. 2002;15(10 Pt 2):1297-300.

9. Mesnil M, Capdevila X, Bringuier S, Trine PO, Falquet Y, Charbit $\mathrm{J}$, et al. Long-term sedation in intensive care unit: a randomized comparison between inhaled sevoflurane and intravenous propofol or midazolam. Intensive Care Med. 2011;37(6):933-41.

10. Rutman MS. Sedation for emergent diagnostic imaging studies in pediatric patients. Curr Opin Pediatr. 2009;21(3):306-12.

11. Slonim AD, Ognibene FP. Sedation for pediatric procedures, using ketamine and midazolam, in a primarily adult intensive care unit: a retrospective evaluation. Crit Care Med. 1998;26(11):19004.

12. Cheuk DK, Wong WH, Ma E, Lee TL, Ha SY, Lau YL, et al. Use of midazolam and ketamine as sedation for children undergoing minor operative procedures. Support Care Cancer. 2005;13(12):1001- 